\title{
ADVANTAGES OF TENSILE STRUCTURES OVER OTHER SPACE FRAME STRUCTURES
}

\author{
Aniket N. Tolani ${ }^{1}$, Aniket S. Patil ${ }^{2}$, Ganesh N. Patil ${ }^{3}$, Vedang H. Vadalkar ${ }^{4}$, P. R.Barbude ${ }^{5}$

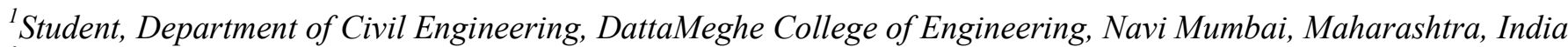 \\ ${ }^{2}$ Student, Department of Civil Engineering, DattaMeghe College of Engineering, Navi Mumbai, Maharashtra, India \\ ${ }^{3}$ Student, Department of Civil Engineering, DattaMeghe College of Engineering, Navi Mumbai, Maharashtra, India \\ ${ }^{4}$ Student, Department of Civil Engineering, DattaMeghe College of Engineering, Navi Mumbai, Maharashtra, India \\ ${ }^{5}$ Assistant Professor, Department of Civil Engineering, DattaMeghe College of Engineering, Navi Mumbai, \\ Maharashtra, India
}

\begin{abstract}
Tensile structures have been in use since ancient time. The most rudimentary applications could be seen in the form of tents and other temporary roofing used by nomadic tribes. These structures exhibit non-linear behavior, as opposed to linear relationships observed in conventional structures, which use steel as its primary material resource. The non-linear relationship can be observed in geometry as well as in material aspects. Tensile structures satisfy both, the architect's design of attractive elevation as well as the structural designer's overall economic design by considerable reduction in the amount of steel employment. Due to their light weight characteristics, in most of the cases, earthquake effects are not considered whereas wind is a critical factor. The fabric only resists tensioning and has almost no compression or bending. Due to characteristic of fabric to stretch long spans, these structures can be employed on places such as stadiums and aircraft hangar parking areas, where large column free spaces are required. A general discussion on various aspects such as material properties, design convention, economic counter views have been considered, which are essential during the designing of the tensile structures. These have been presented in the first part of this paper. The second part focuses on comparison of tensile structures over space frames structures which are generally used for covering areas. The area selected for the stated purpose is an entrance canopy. Computer aids like Staad. Pro and FormFinder are used. The end conclusion, which the study aims to show, is that the tensile membrane structure could outmatch the conventional systems in terms of construction difficulties, economic liabilities and resource/material requirement.
\end{abstract}

Keywords: Tensile Structures, Membrane Structures, Column-Free Spaces, Light Weight Structures, Form-Finding, FormFinder

$* * *$

\section{INTRODUCTION}

Tensile structures still lag behind in their popularity as most of the codes have still not mentioned the design of these structures for general construction practices. These structures have very less literature published for Structural Engineers to become aware of this new emerging technique and hardly any university has included the topic in their curriculum. A detailed understanding of membrane structures has yet to be developed, as these structures have a comparatively more recent history. Membrane type structures have properties which make them distinctive and influence their use over other conventional forms. The fabric resists the tensile stresses which are developed due to forthcoming critical wind loads.

These membrane enclosures function both as load bearing structures and building envelope. These day, the issue of resource scarcity applies not only to material but also to energy and here again these structures have a role to play. The fabric skin acts as passive filter capable of modifying both thermal light levels within the enclosed spaces to minimize the reliance on conventional energy sources.

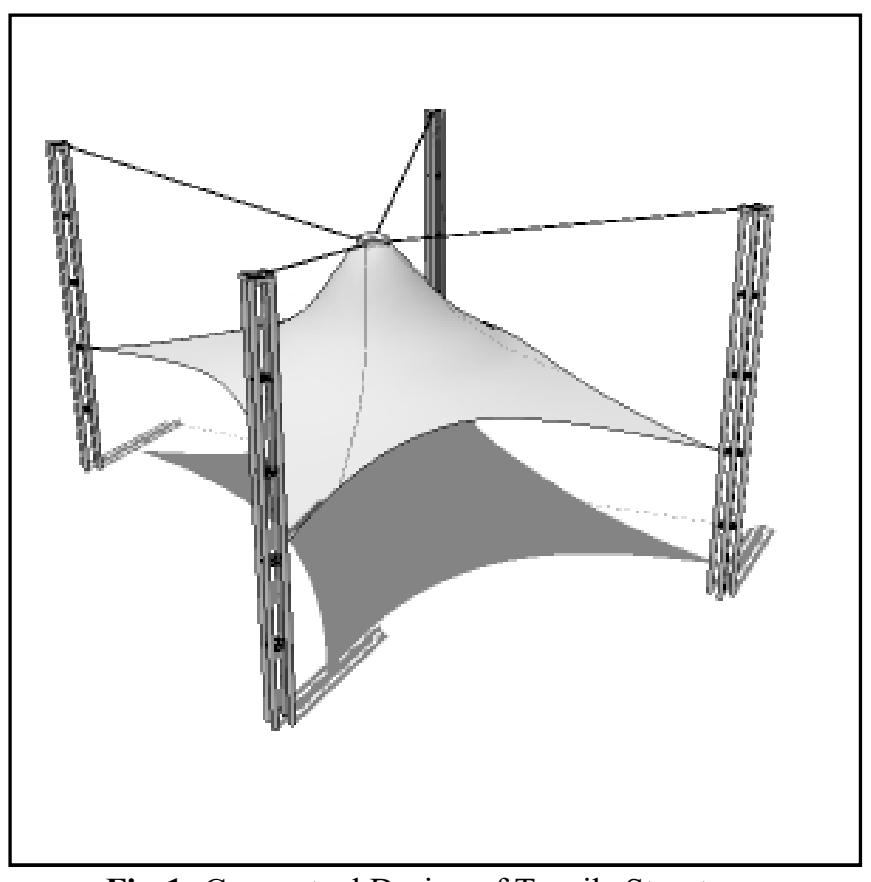

Fig-1: Conceptual Design of Tensile Structure 


\section{MATERIALS}

A major distinguishing factor when it comes to tensile structures is the material used. As the name suggests, these structures use sheets of woven fabrics coated with polymeric resin for this purpose. The coating is useful for the following purposes:

- The yarn can be protected against abrasion.

- The yarn can be protected against UV damage.

- It helps in stabilizing the unstable fabric geometry.

- It helps in seam joints during the fabrication stages.

The base material used for the development of the membranes yarns are polyester or resin drawn threads which are combined together to form a thicker strands varying between thickness of 3 to 25 microns based on the requirement of the different projects.

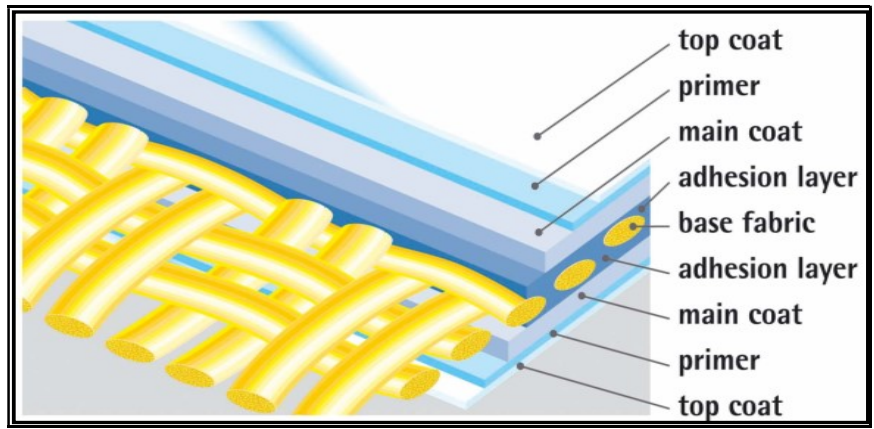

Fig-2: Cross Sectional View of Fabric

Other materials used for the strands are Glass, Aramids and Liquid Crystal Polyester. Other materials are under research for similar purposes. The yarns are manufactured by specific agencies and are patented to prevent their misuse. The materials used for the yarn strands are judged on the following factors:

- Filament diameter.

- Number of elementary filaments. These decide the thickness of the strands.

- Linear density of the strands.

- Number of twist per meter length.

- Finishing treatment such as the coating provided and the chemical processes to which the yarn is subjected to.

Table no: 1 Different types of fabric structural geometry

\begin{tabular}{|c|c|c|}
\hline COATED FABRICS & OPEN MESH & FOILS \\
\hline $\begin{array}{l}\text { Coated fabrics pose to be orthogonally } \\
\text { shaped i.e. they are aligned perpendicular to } \\
\text { each other. They even possess symmetry. } \\
\text { While the structural function is provided by } \\
\text { the yarnsthe coating provides a protective } \\
\text { layer. }\end{array}$ & $\begin{array}{l}\text { Open mesh are used more for aesthetic } \\
\text { purposes rather than structural utility. } \\
\text { These have, as the name suggest, mesh } \\
\text { like form/openings. They are used when } \\
\text { weather is pleasant and welcoming. }\end{array}$ & $\begin{array}{l}\text { Architectural foils are relatively new } \\
\text { but have found application in } \\
\text { pneumatic structures. The } \\
\text { mechanical properties of these } \\
\text { aren't suitable for single skin } \\
\text { envelopes. }\end{array}$ \\
\hline
\end{tabular}

\subsection{Material Used For Coating and Their}

\section{Properties:}

The woven yarns can't be used without treating them to withstand external forces such as abrasion due to extreme weather, chemical interaction, and temperature changes. The coating is done to so as to strengthen the bond between strands and impart them with extra tensile strength. Materials used for coating purposes are:

- PVC coated polyester fabric

- PTFE coated glass fabrics

- Silicone coated glass fabrics

- ETFE foils

\subsubsection{PVC Coating:}

PVC stands for Polyvinyl Chloride and is applied on the fiber as a paste. PVC seems to improve the thermal properties of the yarn, provide better surface aspects and help in cleaning. For fire resistance a secondary coat of plasticizes are applied such as phtalates, phosphates or esters. PVC can be pigmented for imparting color and light stability. The PVC coat is implanted with stabilizing molecules to provide thermal, oxidation and UV protection.

\subsubsection{PTFE Coating:}

PTFE stands for Polytetrafluoroethylene. It is the most commonly used coating material as very few coating materials can provide such versatile and outstanding properties. All this is possible because of the chain arrangement of the tetrafluoroethylene monomers. It is one of the best thermal insulators as it can sustain high thermal temperatures and has a relatively low thermal conductivity coefficient. Highly resistive against abrasion and corrosive substances such as hydrochloric acid or sulphuric acid. They are inert against most environmental pollutants such as industrial gases and traffic fumes. PTFE coating is hydrophobic and hence cleaning it is very easy. It even readily absorbs UV radiation and acts as a self-sufficient antioxidant and plasticizer.

\subsubsection{Silicone Coating:}

Silicone coating is obtained by cross linking of silicone macromolecules. The chain of silicone is applied on the yarn to provide it with the protective coating. The advantage of using silicone is that the chain of molecules can be combined with different chemical combinations to obtain the coating with the specific property as per required by the structure. For example silicone based substrate are 
combined with glass to form a covalently to create a hydrophobic film coating.

\subsubsection{ETFE Foil:}

ETFE stands for Ethylene tetrafluoroethylene. It is a copolymer of ethylene and tetrafluoroethylene which has a very high melting point ranging in $250^{\circ} \mathrm{C}$ to $270^{\circ} \mathrm{C}$. The foils have a translucency advantage as opposed to other materials. It can transmit about $90 \%$ of the incident light. Another advantage is the distribution of stress. ETFE foils have a bilinear elastic isotropic distribution behavior.

\subsection{Properties}

\subsubsection{Weather Resistance of Materials}

Weathering in polymer is a major concern and is definitively caused by the exposure to UV radiation, moisture, temperature, and humidity. For accuracy and controlled testing, artificial weathering rather than natural weathering or accelerated natural weathering is relied on. The Xenon Arc Lamp test is the standard testing procedure used for this purpose. The xenon arc test consist of a test chamber which reproduces the damage caused by the full spectrum of sunlight. Another testing method would be the Fluorescent UV test. Similar to the Xenon Lamp, this test too uses a closed chamber which has 2 sets of UV lamps, a short range based and a long range based. Depending on the requirement, the lamps are used to test the polymer. As in the Xenon Arc Lamp test, factors such as temperature, humidity, moisture, and dew are regulated to mimic the environmental conditions.

\subsubsection{Thermal Properties of Membrane Materials}

In polymers it has been seen that the thermal conductivity seems to decrease steadily under the melting point. It behaves a lot like an amorphous polymer. The thermal conductivity is very much dependent on the chain segment orientation. The polymers can be reinforced during manufacturing process for specific demands of thermal conductivity. But during the use of membranes as a tesnsile canopy, the designer end up doing two things to counter this issue. They first of all use a two-layer or a multi-layer membrane structure. And they provide an air buffer of about 25 to $30 \mathrm{cms}$ in between them.

\subsubsection{Fireproofing Properties of Membrane}

\section{Materials}

Fire safety is a major factor in selection of membranes. These membranes are to be used as a medium to polarize sunlight and use it as an aesthetic formwork. The use of sunlight can't be segregated from the heat discharged by the rays of sunlight. The fabric itself, being a low thermal conducting material, the probability of ignition is high. Under such situation, the safety of the users becomes jeopardized. To prevent the loss of human lives, research was conducted to come up with coatings which ca help us counter this issue. Hence it was found that PVC gave results which were coherent with the requirements. PVC membranes have been found to burn through under 4 minutes mark and form a hole on the surface without harming the configuration of the yearn. The opening is utilized for the removal of smoke. This prevents deaths by choking. . Early occurrence of the hole results in the emission of heat $\&$ smoke from the building and postpones the collapse of the steel structure, which is beneficial for staff in public

Table no: 2 Properties of Coating Materials

\begin{tabular}{|c|c|c|c|c|}
\hline & $\begin{array}{lll}\text { PVC } & \text { Coated } & \text { polyester } \\
\text { fabrics }\end{array}$ & $\begin{array}{l}\text { PTFE Coated glass } \\
\text { fabrics }\end{array}$ & $\begin{array}{l}\text { Silicone coated glass } \\
\text { fabrics }\end{array}$ & $\begin{array}{l}\text { PTFE Coated } \\
\text { PTFE fabric }\end{array}$ \\
\hline $\begin{array}{ll}\begin{array}{l}\text { Tensile } \\
\text { (warp/weft) } \mathrm{kN} / \mathrm{m}\end{array} \\
\end{array}$ & $115 / 102$ & $124 / 100$ & $107 / 105$ & $84 / 80$ \\
\hline 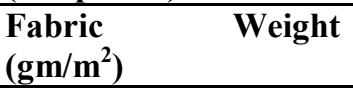 & 1200 (type 3) & 1200 (type G5) & 1100 & 830 \\
\hline $\begin{array}{ll}\text { Trapezoidal } & \text { tear } \\
\text { warp/weft (N) } & \end{array}$ & $800 / 950$ & $400 / 400$ & $960 / 700$ & $925 / 925$ \\
\hline $\begin{array}{l}\text { Visible Light } \\
\text { transmission (\%) }\end{array}$ & $10-15$ & $10-20$ & $<80$ & $19-38$ \\
\hline $\begin{array}{l}\text { Flexibility/crease } \\
\text { recovery }\end{array}$ & High & Low & High & High \\
\hline Cleaning & Easier at the top & Self-cleansing & Self-cleansing & Self-cleansing \\
\hline Seam connections & High Frequency & Thermally & Vulcanization & Stitching \\
\hline Life span (years) & $>15-20$ & $>25$ & $>25$ & $>30$ \\
\hline Cost & Low & High & High & High \\
\hline Significance & $\begin{array}{l}\text { They make the membrane } \\
\text { more colorful and } \\
\text { aesthetically pleasing. } \\
2 . \\
\text { Ease for welding operations. }\end{array}$ & $\begin{array}{l}1 . \\
\text { Large prestress } \\
\text { hence greater support } \\
\text { system. } \\
2 . \\
\text { Sturdy and can resist } \\
\text { harsh winds. }\end{array}$ & $\begin{array}{l}1 . \\
\text { High resistance to } \\
\text { chemical and } \\
\text { corrosion. } \\
2 . \\
\text { High thermal } \\
\text { insulative property. }\end{array}$ & $\begin{array}{l}1 . \\
\text { Low friction, hence } \\
\text { ease of cleaning. } \\
2 . \text { High life } \\
\text { expectancy. }\end{array}$ \\
\hline
\end{tabular}




\section{LOAD CONSIDERATIONS}

Even a small change in the loading conditions can affect the deflection patterns considerably. Membrane structures have to undergo pretension so that the fabric will achieve the predefined pre-stress levels at the correct geometry once the creep of the membrane has occurred. These structures are very light weight and so they have hardly any impact of the acceleration produced from the ground, in case of earthquakes. So in most of the general cases earthquake loads are not considered in design of these structures. Uplift Wind Pressure is the critical case for membrane and cable stresses in case where cables are used as boundary supports. It is generally considered as a static load case, defined by a dynamic pressure multiplied by a pressure coefficient $(\mathrm{Cp})$.

\section{THE DESIGN PROCESS}

"Formfinding" is a process by which initial shape of membrane is obtained. This process guarantees that the overall shape is statically balanced. It is crucial to verify the warp and weft forces arising into the fabric and also their compliance with the boundary conditions. The architect's exquisite shape and the engineer's structural constitution should reverberate and bring elegance along with economy. The design is completely based on the material properties and is reliant on the behavior of fabric under loading therefore the structural designers and manufacturers should be involved in the process from initial stages on design only. The design process basically follows three main steps: Formfinding, static analysis and dynamic analysis.tatically balanced. It is crucial to verify the warp and weft forces arising into the fabric and also their compliance with the boundary conditions. The architect's exquisite shape and the engineer's structural constitution should reverberate and bring elegance along with economy. The design is completely based on the material properties and is reliant on the behavior of fabric under loading therefore the structural designers and manufacturers should be involved in the process from initial stages on design only. The design process basically follows three main steps: Formfinding, static analysis and dynamic analysis.

\subsection{FormFinding:}

According to Lewis (2003), Form finding may be defined in the following ways: "Form finding is the iterative process through which a designer arrives at the optimal shape that the membrane can adopt under the various static and dynamic loads." The membrane is never subject to constant loads. Hence an approximate method needs to be implemented. The process of formfinding basically depends on the boundary conditions which decide the shape of the structure. After the shape is decided the warp and weft forces are verified and the stresses in fabric are evaluated using the various computer aids like FORMFINDER, NISA etc.

\subsection{Static Equilibrium}

To check the deflection that is occurring due to various load cases and combinations, static analysis is done. While designing structures it becomes vital to consider different load combinations taking into account the unpredictability of magnitude and direction. The same curvature which is obtained by formfinding is taken and analysis is done to check the permissible deflections. Colour patterns provide a helping-hand in illustrating deflection patterns. Theevaluation of stresses is an important process in the design of tensile structures as it determines the type of material to be used, the form of material to be used and the angle at which the warp and weft directions are aligned with each other..

\subsection{Dynamic Equilibrium}

The dynamic analysis evaluates the relation between the fluctuating applied loads and the structural geometry. As wind is the critical load under consideration, the main objective of performing dynamic analysis is to check the stability of membrane under varying wind load cases arising from various directions. Even a small variation in deflection of structure may lead to a considerable damage in particular cases. To achieve this accuracy for dynamic loading, wind tunnel tests can be performed. The objective of the process is to calculate the wind forces/stresses which act as the critical boundary conditions needed by the software.

\subsection{Patterning}

Patterning is generally an analytical process performed for determination of geometric properties of space enclosed using fabric. The spatial form as obtained from formfinding process is converted into two dimensional cutting forms. In absence of computer aids physical modeling was preferred, but now computer aids are used on account of their betterlevel of accuracy.

\section{COMPARATIVE STUDY OFTENSILE STRUCTURES OVERSPACE FRAME STRUCTURES}

As these forms of structures are very new into the world of structural engineering, a basic introduction has been provided in the first part.

The second part focuses to compare Tensile structures over the conventional space frame structures on account of their cost benefits, light weight characteristics, durability characteristics, shortened construction schedules and attractive elevation.

\subsection{General Aspect:}

The area under consideration in this case is an Entrance foyer for a 19 story building; The Haj House, which is located near J. J. flyover in ChhatrapatiShivaji Terminus Area, Mumbai, India. The area is currently covered using 
tensile fabric. The study emphasis to show that if as an alternative space frame was constructed instead of tensile canopy then how much would the factors under consideration would vary. Indian Standard Codes are used for required data and design considerations. As per IS 875-3 (1987): Code of Practice for Design Loads (Other than Earthquake) for Buildings and Structures, Part 3: Wind Loads, the basic wind speed of Mumbai is taken as $44 \mathrm{~m} / \mathrm{s}$. and Design wind pressure is calculated as $745.12 \mathrm{~N} / \mathrm{m}^{2}$.

\subsubsection{Governing Load Combinations:}

1. Dead Load + Imposed Load.

2. Dead Load + Wind Load (UP).

3. Dead Load + Wind Load (DOWN)

\subsubsection{Materials Properties:}

1. All mild steel part shall have minimum Young's modulus of $2.1 \times 10^{10} \mathrm{~kg} / \mathrm{m}^{2} \&$ density equal to 7850 $\mathrm{kg} / \mathrm{m}^{3}$. Tubular pipes are used as columns. GI sheets for roof covering.

2. Fabric material used is MEHATOPValmex Product no. FR 700 Type I with polyester plane weave, having a weight of $700 \mathrm{gsm}$, thickness $0.6 \mathrm{~mm}$ and a tensile strength of $60 \mathrm{KN} / \mathrm{m}$. This fabric is manufactured by MehlerTexnologies, a German Company involved in Manufacture of Tensile and other Fabrics.

\subsubsection{Software Used:}

Staad.Pro - For all Steel Design and Analysis, Staad.Pro is used.

Formfinder - The modelling and analysis of Tensile Fabric is done using Formfinder. The estimated stress is evaluated and a fabric based on that is selected.

M.S.EXCEL - Graphs are plotted on Microsoft Excel.

\subsection{Design of Tensile Canopy:}

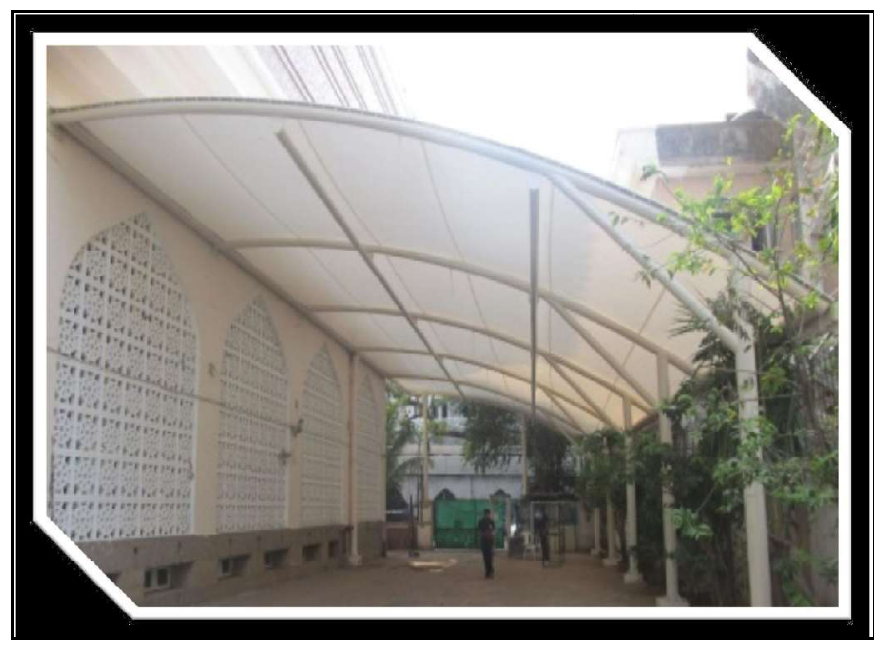

Fig-3:General View of Tensile Canopy

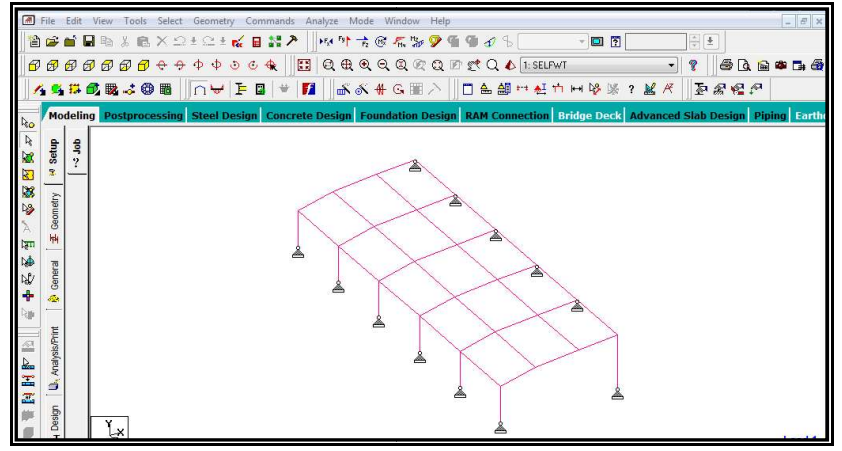

Fig-4: Structural Frame

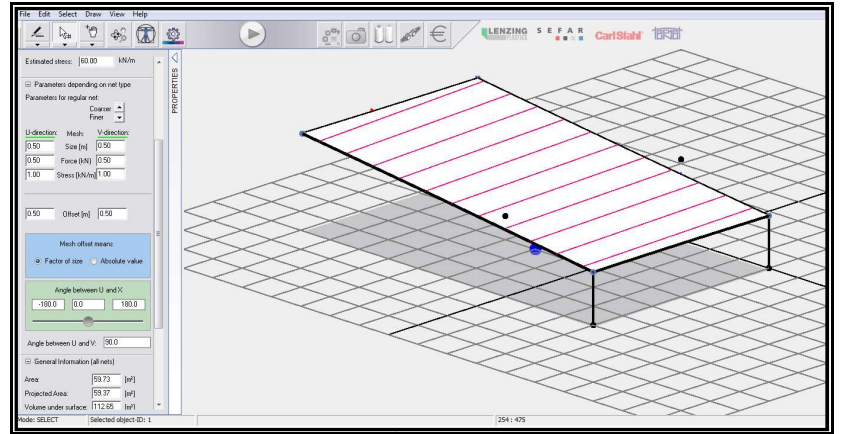

Fig-5:One Panel of Tensile Roof (Drawn Using Formfinder Software)

\subsection{Design of Space Frame}

On same area to be covered as an alternative solution Space Frame is designed.

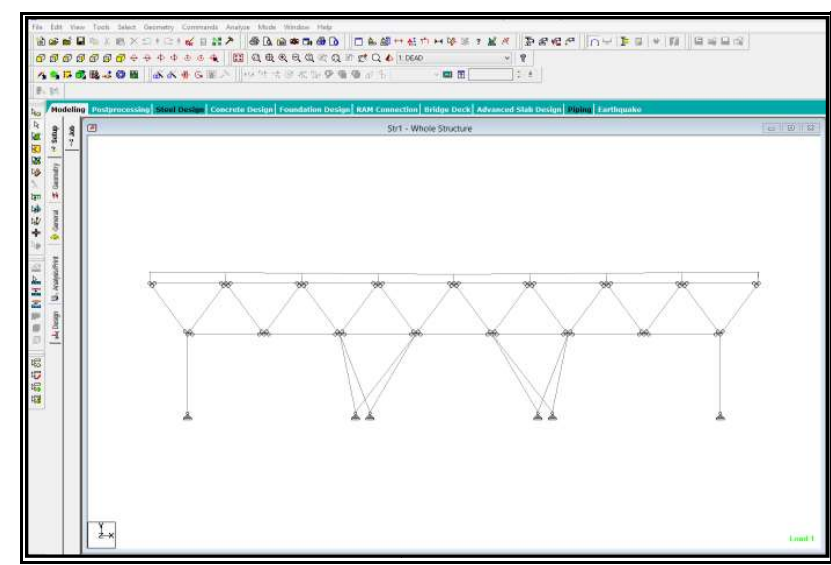

Fig-6: Elevation of Space Frame on STAAD.PRO

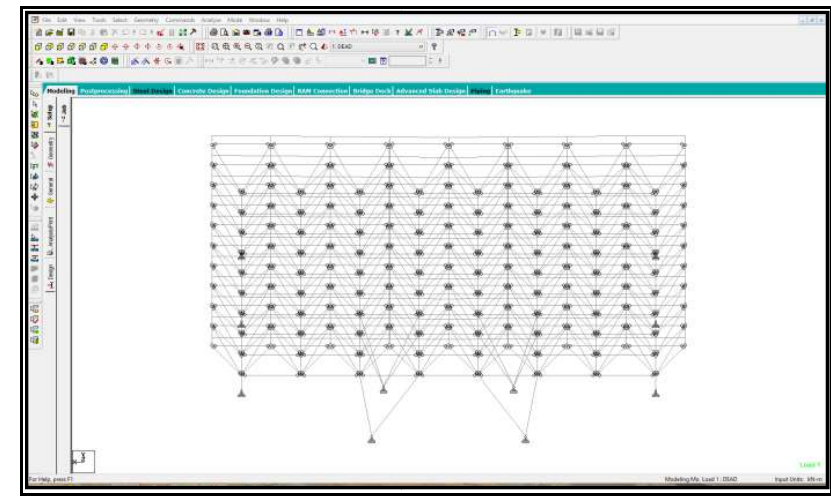

Fig-7:Isometric View of Space Frame on STAAD.PRO 


\subsection{Design Results:}

5.4.1 Design results of Tensile canopy:

\begin{tabular}{|c|c|c|c|}
\hline \multicolumn{4}{|c|}{ STEEL TAKE-OFF } \\
\hline & PROFILE & LENGTH (MET ） & WEIGHT (KN \\
\hline & PIP2191L & 22.50 & 5.583 \\
\hline & PIP1651I & 120.84 & 21.072 \\
\hline & PIP1397I & 60.00 & 8.804 \\
\hline & & TOTAL = & 35.459 \\
\hline
\end{tabular}

Fig-8: Steel Take off of Structural Frame of Tensile Structure

Total Steel requirement $=35.459 \mathrm{KN}$

Total Fabric requirement $=3400 \mathrm{ft}^{2}$.

\subsubsection{DESIGN RESULT OF SPACE FRAME}

\section{STRUCTURE}

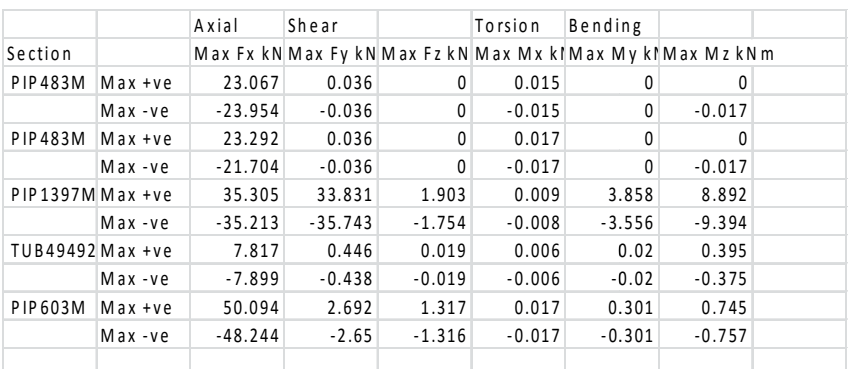

Fig-8:Forces and Moments in Tubular Sections Used In Space Frame

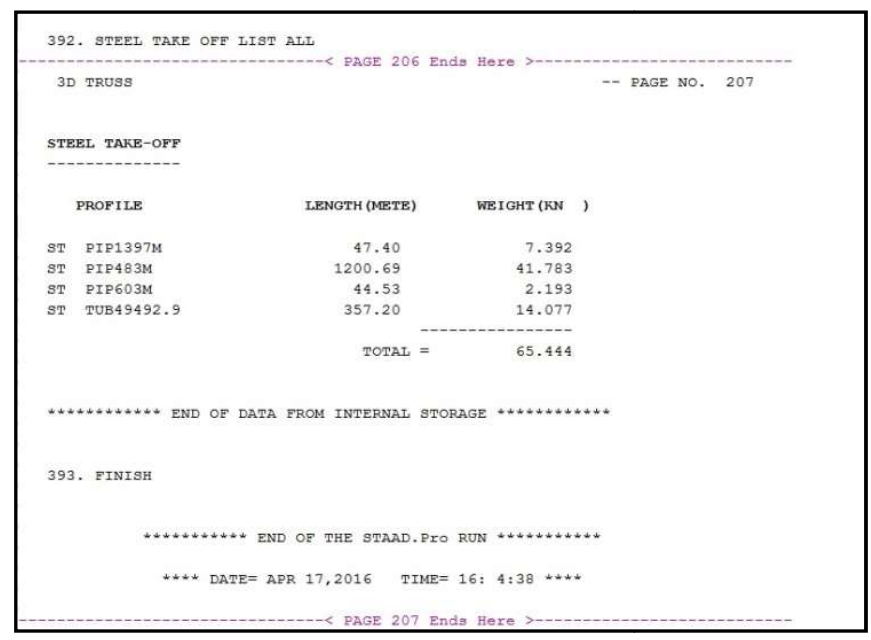

Fig-9:Steel Take off of Structural Frame of Space Frame

Adding approximately $15 \%$ for the weight of GI sheets and Connections

Total steel Requirement $=75.25 \mathrm{KN}$

\section{SUMMARY}

The Design of Steel frame of canopy and Space Truss was completed using Staad.Pro Software and the results are tabulated from the Analysis Report. Design of both the Structures was optimized for all the governing factors. The Design of both structures was used to derive the steel outtake, economic liability and material specification. Results are summarized on the following basis:

\subsection{Overall Material Cost of Structure:}

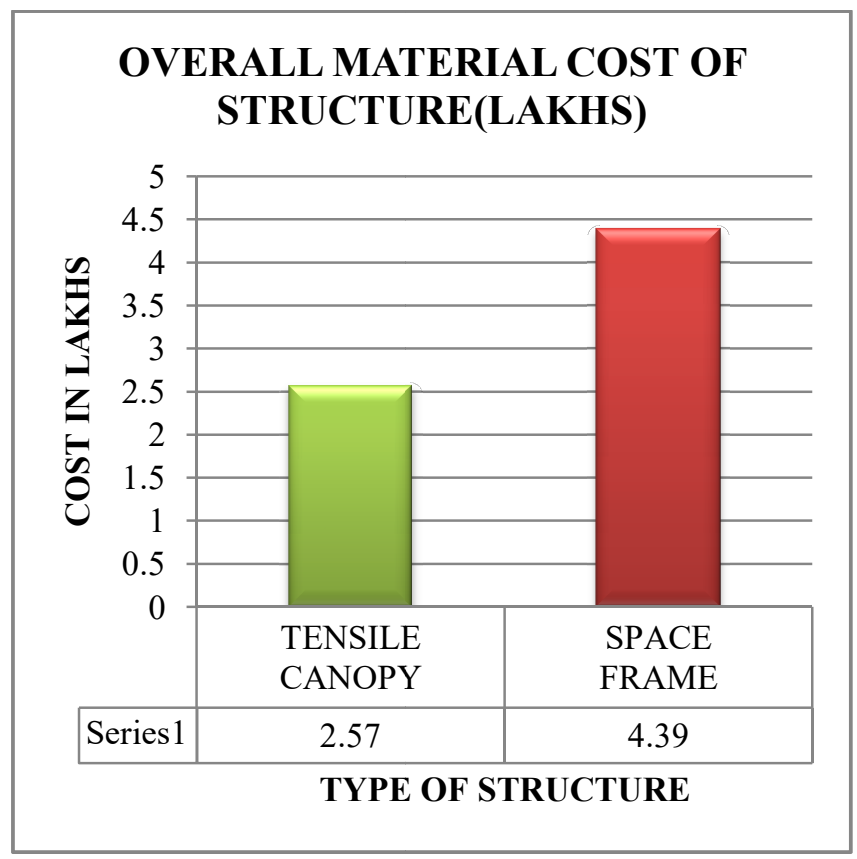

Chart no: 1 Overall Material Cost of Structures

From client's point of view Installation cost of a structure should be as minimum as possible.Material cost is major cost of construction. As it is shown by graphical representation, cost of material of tensile structure including steel and fabric is quite less as compared to space frame structure

\subsection{Overall Weight of Structure:}

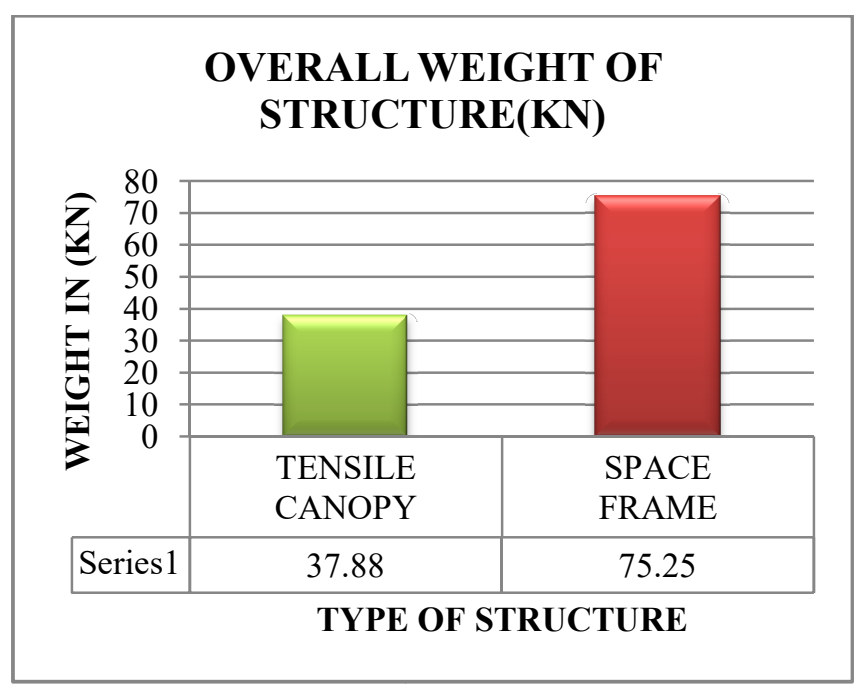

Chart no: 2 Overall Weight of Structure 
Though an economic design, it should also be safe against the various predictable and unpredictable forces. Overall weight of structure is carried out to show that inclusive of the fabric the weight of structure is quite less as compared to space frame structure. Also space frame structure is a large steel mesh as compared to a composite structure like tensile structure, so in case of unexpected collapse of structure, fabric being a flexible material will be safe as compared to steel.

\subsection{Amount of Steel:}

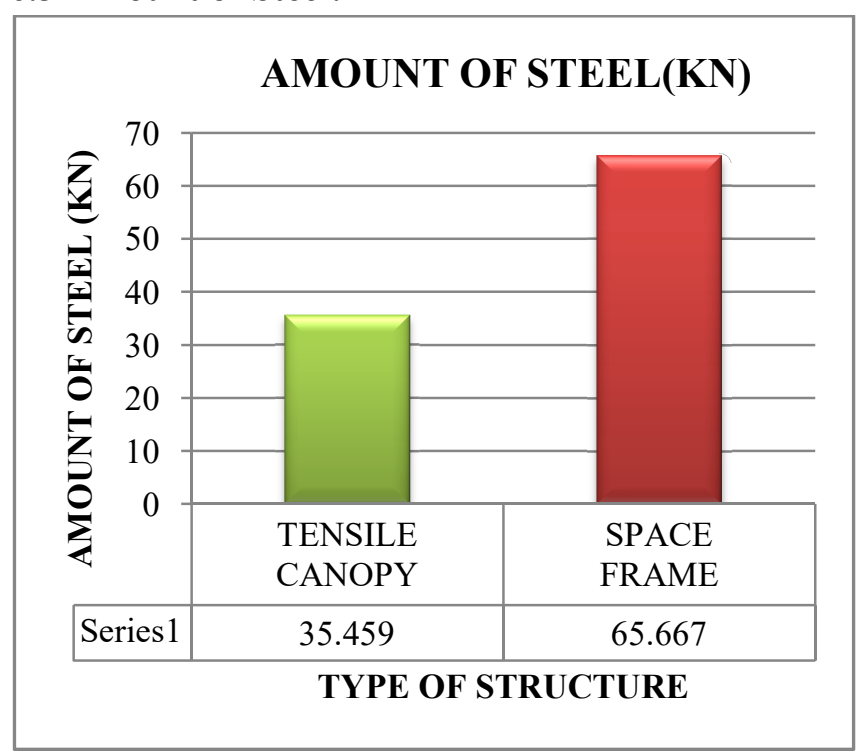

Chart no: 3Amount of Steel Required for the Structures

The cost of a structure goes on increasing with its life, on account of its maintenance and repair charges, which depend on the durability of the material used. The warranty of the fabric as given by most of the manufacturers is around 1520 years, but studies have shown fabrics have considerable good functioning upto 25-30 years too. Also tensile structures have very less amount of steel requirement as compared to space frame structure, so there are less maintenance charges to avoid corrosion of steel and also the dismantling of members for repairs is not required.

\section{CONCLUSION:}

This comparative study showcases the superiority of the tensile structures as compared to the conventional steel structures for covering large areas. The advantage of using tensile canopy is apparent as shown with the help of the graphs. It is not only a cost effective solution but also an aesthetically pleasing one too. The tensile structures are a relatively newer concept which is just entering the Indian construction scenario and quickly gaining popularity. The following are the areas where the tensile structure outclasses the conventional forms of structures:

\section{- Cost Benefits}

As from the graph it is seen that there is a significant 50$60 \%$ cost benefit over conventional systems. The case study shows that the total cost of steel required for covering a specific area with space frame is found to be much greater than the cost of membrane used to cover the same area. The additional cost benefit is that membrane structure provides us with easy and efficient ventilation (both air as well as light) which in turn reduces the electricity bills.

\section{- Lightweight Nature And Earthquake Resistance}

The weight of the membrane in tensile structures is very less and consequently, the quantity of structural steel utilized to support the membrane is also minimal. Thus, the weight as well as the overall cost of tensile structures is much less as compared to conventional roofing systems. As less steel is utilized, more useful space free of columns becomes available. As the weight of the structure is so little, it will not experience much acceleration forces under seismic action. As is evident from the above given comparative graphs it is found that the total reduction in steel consumption when using tensile structures as opposed to the conventional forms of the structures is about $50-60 \%$ in each case.

\section{- Low Maintenance}

In case of space frames, the major difficulty is the corrosion of steel. The regular maintenance, such as painting, coating, etc. needs to be done, which sums up to be a considerable cost. While in case of membrane structure, membrane itself is resistant to corrosion. As the steel used is very less, only at connections and supports, that is the only part need to be taken care of. Also the self-cleaning membrane material can be used.

\section{- Excellent Durability}

The membrane material itself can withstand within the range of -40 o $\mathrm{C}$ to +70 o $\mathrm{C}$. Companies provide about $10-15$ years of warranty for their fabrics and usually the minimum life span of these structures is about 25 years.

\section{- Shortened Construction Schedules}

The erection of the tensile structures takes less than a week to complete as all the patterning \&amp; fabrication works are mostly carried out in warehouses and the structure is erected on site. The construction period is only the time required for its erection, which can be reduced to minimum by using advanced construction equipment and techniques.

\section{- Flexible Design Aesthetics}

Membrane structures can be designed, analysed and erected in any of the shape or form we require. It provides extra space for the designer to experiment with different shape. The membrane fabric can even incorporate natural and artificial lighting, which can add another aesthetic dimension to them.

\section{ACKNOWLEDGEMENT}

The photos used in this article have been sourced from the internet and we wish to acknowledge them. 


\section{REFERENCES}

[1] Space Structures: Principles and Practice, N. Subramanian, Volume 1, Multi-Science Pub.2006

[2] European Design Guide for Tensile Surface Structures, Brian Forster Marijke

Mollaert, Vrije Universiteit Brussel. Scientia Vincere Tenebras, 2004.Tensinet.

[3] Tensioned membrane structures J. Schlaich, R. Bergermann, W. Sobek'. Invited Lecture In The LassCongress In Madrid. September 1989

[4] Conceptual Design and Analysis of Membrane Structures,EricaHenrysson. Department of Applied Mechanics, Division Of Material And Computational Mechanics.Chalmers University Of Technology.

[5] Horst Berger, Light Structures - Structures of Light, birkhauserverlag, Basel, Switzerland,1996

[6] Environmental behaviour of tensile membrane structures - amiraelnokaly*, John Chilton andRobin Wilson, School of the Built Environment, University of Nottingham, 2000.

[7] Tensile structures, Prof Schierle, American Institute of Architects.

[8] Is 800-2007general Construction In Steel - Code Of Practice(Third Revision)

[9] IS 806-1968 (Reaffirmed 2008): Code of practice for use of steel tubes in general BuildingConstruction.

[10]IS 1161-1998: Code of practice for use of steel tubes for structural purposes Specification.

[11] Membrane Materials And Membrane Structures In Architecture, Di Tian, The University Of Sheffield, School Of Architecture, September 2011.

\section{BIOGRAPHIES}

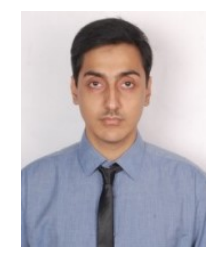

\section{Aniket N. Tolani}

Student,

Final Year Civil Engineering,

DattaMeghe College of Engineering, Airoli.

Email ID: aniket.tolani.at@gmail.com

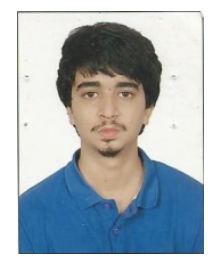

\section{Aniket S. Patil}

Student,

Final Year Civil Engineering

DattaMeghe College of Engineering, Airoli.

Email ID: aniketpatil.aiesec@gmail.com

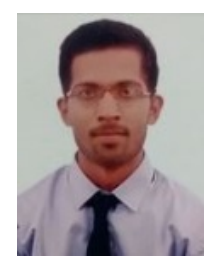

\section{Ganesh N. Patil}

Student,

Final Year Civil Engineering

DattaMeghe College of Engineering, Airoli.

Email ID: shreeg.n.patil95@gmail.com

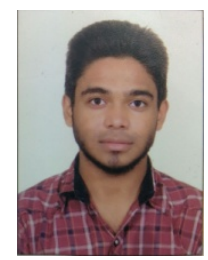

\section{Vedang H. Vadalkar}

Student,

Final Year Civil Engineering

DattaMeghe College of Engineering, Airoli.

Email ID: vadalkarvedang11@gmail.com

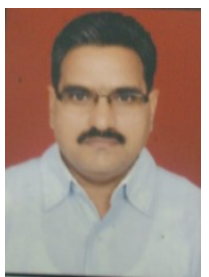

GUIDE:

Er. Prashant R. Barbude

Assistant Professor,

Civil Engineering Department,

DattaMeghe College of

Engineering,Airoli

Email ID: prbarbude@yahoo.com 